\title{
Anaplastic carcinoma of the thyroid - clinico- morphological spectrum and review of literature
}

\author{
Ghosh A ${ }^{1}$, Nepal N ${ }^{1}$, Gharti MD ${ }^{1}$, Basnet $\mathrm{S}^{1}$, Baxi $\mathrm{M}^{2}$, Talwar $\mathrm{OP}^{1}$ \\ ${ }^{1}$ Department of Pathology, Manipal Teaching Hospital and Manipal College of Medical Science, Phulbari, Pokhara, Nepal \\ ${ }^{2}$ Department of Surgery, Manipal Teaching Hospital and Manipal College of Medical Science, Phulbari, Pokhara, Nepal
}

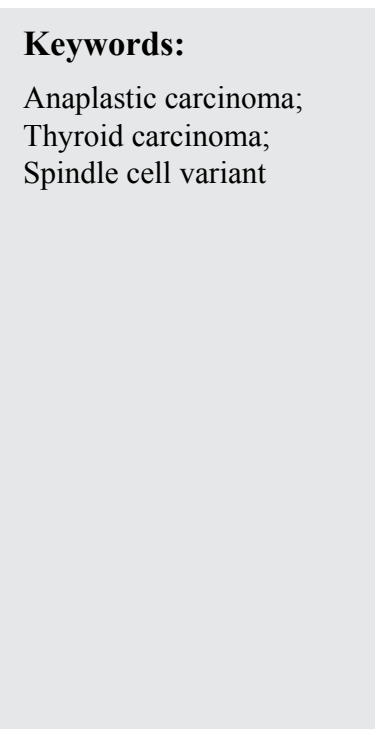

\begin{abstract}
Background: Thyroid cancer is fairly common. The worldwide annual incidence ranges from 0.5 to 10 cases per 100,000 people. Anaplastic thyroid carcinoma, comprising less than $10 \%$ of all thyroid carcinomas, remains one of the most virulent of all cancers in humans with a 10 year survival rate of only $0.1 \%$. In the present study we looked into the clinical, cytological and histological spectrum of anaplastic carcinoma and compared our experience with recent literature.
\end{abstract}

Materials and Methods: This was a hospital based retrospective study from January 2000 to November 2010. Clinical, cytological and histopathological data of all the diagnosed anaplastic thyroid carcinoma cases were reviewed and analyzed.

Results: Of the 59 thyroid malignancies diagnosed in the same period, 7 cases were anaplastic carcinoma. The mean age was 63 years and was predominantly found in females. All of the cases presented with a neck mass that lasted for a mean of 5.7 months. The mean tumor size was $14.9 \mathrm{~cm}$ and the most common sub-type was the spindle cell type. Atypical mitosis of more than 5 per high power field and necrosis was noted in all cases.

Conclusion: Due to the markedly aggressive nature of this tumor and its association with areas of endemic thyroid disease, early diagnosis and aggressive therapy is essential, especially in the Himalayan and Sub-Himalayan belt.

\section{INTRODUCTION}

Thyroid cancer is fairly common. The worldwide annual incidence ranges from 0.5 to 10 cases per 100,000 people. ${ }^{1}$ Different studies have shown that papillary carcinoma is the most common thyroid cancer and anaplastic carcinoma is relatively uncommon with a frequency of $2 \%-10 \%{ }^{1,2}$

\section{Correspondence:}

Dr. Arnabh Ghosh, MD

Department of Pathology, Manipal Teaching Hospital and Manipal College of Medical Science, Pokhara, Nepal.

Phone no. 061526416 Ext 202
Anaplastic thyroid carcinoma remains one of the most virulent of all cancers in humans with a 10 year survival rate of only $0.1 \% .^{1}$ The mean survival rate is less than 6 months. ${ }^{3}$ The major cause of death of this high grade malignancy is either distant metastasis or is due to the involvement of the vital structures of the neck. ${ }^{1,4}$ In this study we looked into the clinical, cytological and histological spectrum of anaplastic carcinoma and compared our experience with recent literature. 


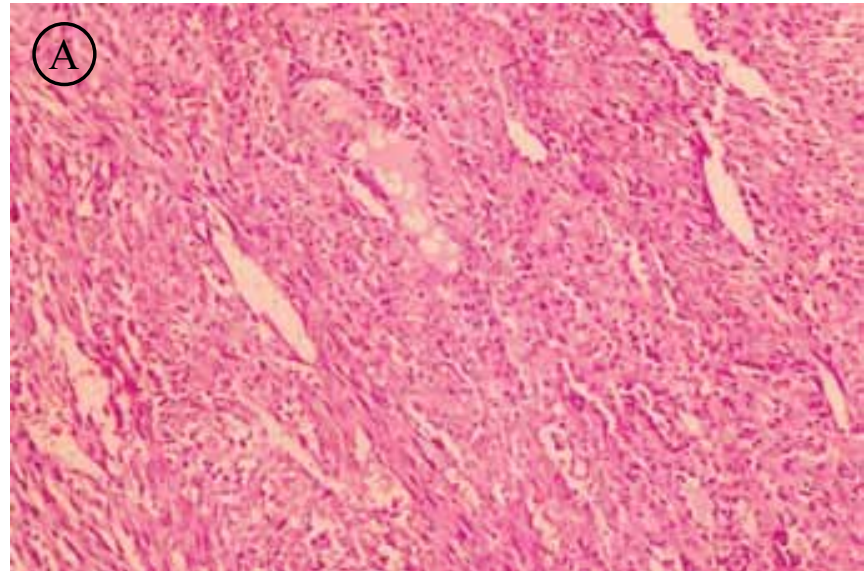

Figure 1-A: Malignant anaplastic carcinoma cells infiltrating between thyroid follicles (HE, X100).

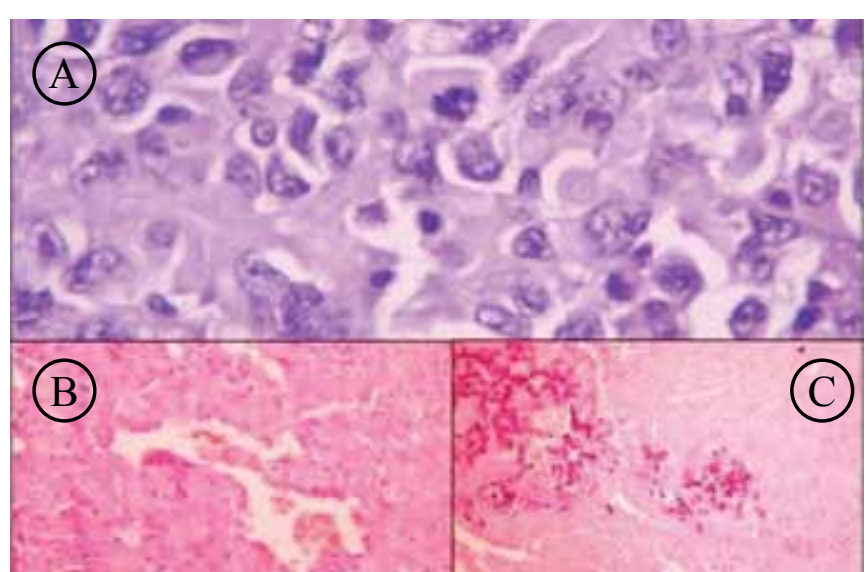

Figure 2.A: Atypical mitosis (HE, X400)

Figure 2.B: vascular embolus (HE, 100x)

Figure 2.C: osseous metaplasia, (HE, 100x),

\section{MATERIALS AND METHODS}

This study was a hospital based retrospective study carried out in the Department of Pathology, Manipal Teaching Hospital, Pokhara. We reviewed all the anaplastic thyroid carcinoma cases that were diagnosed histopathologically along with the respective Fine-Needle Aspiration Cytology (FNAC) during the period between Jan 2000 to Nov 2010. Clinical data was retrieved from the medical records section of the hospital, while pathological data was collected from departmental records. All the FNAC slides were stained with leishman and papanicolaou. All histopathological specimens were processed routinely and stained with hematoxylin and eosin. Multiple sections were studied from the tumor from all of the cases to assess the cytomorphological variation in different foci. Data analysis was done using Microsoft Excel.

\section{RESULTS}

Within the aforesaid period, we diagnosed 59 thyroid malignancies. Of these, we had diagnosed 7 cases $(11.9 \%)$ of anaplastic carcinoma. These 7 cases were initially

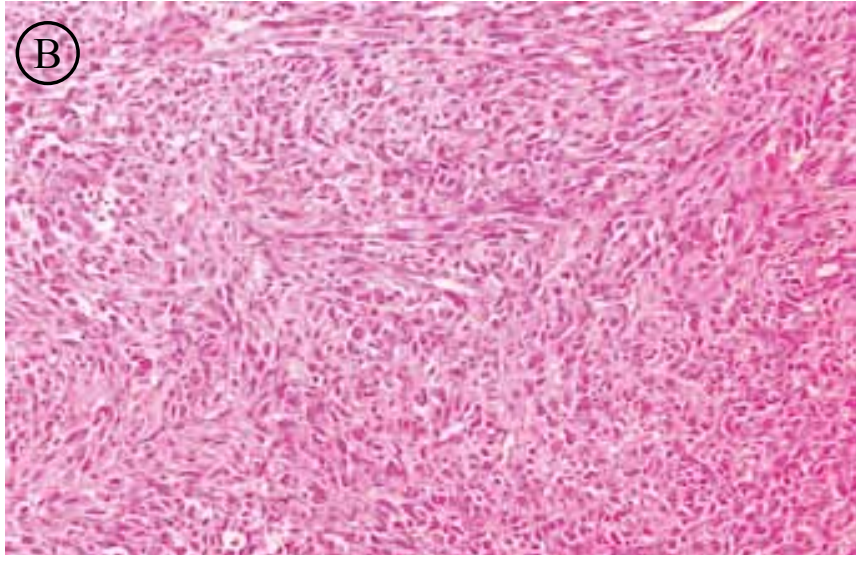

Figure 1-B:. Spindle shaped cells showing prominent storiform pattern (HE, X100).

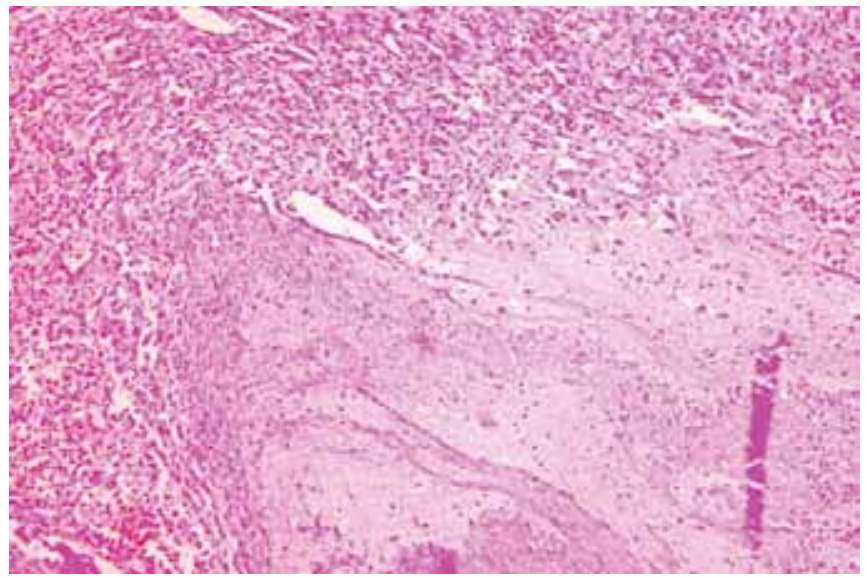

Figure 3: Extensive necrosis -right hand and tumor cells -left hand (HE, X100)

diagnosed with FNAC. The age range of the cases was from 45 to 76 years with a mean age of 63 years. A female preponderance was noted with the male to female ratio being 1:2.4. Every case presented with a rapidly enlarging neck mass that had a duration ranging from 4 to 8 months. 2 of the cases had hoarseness, 1 case had dysphagia and 2 of the cases showed cervical lymphadenopathy (Table 1).

The size of the tumors ranged from 9 to $26 \mathrm{~cm}$ with a mean size of $14.9 \mathrm{~cm}$. Among all cases, 3 cases were of spindle cell variant (fig. 1A and 1B), 1 was of squamoid variant, 1 case showed associated micropapillary carcinoma and 1 case showed papillary formation without features of papillary carcinoma. The surrounding muscle was involved in 3 cases while perineural invasion, capsular invasion and tumor emboli (Fig 2B) were seen in 1, 1 and 2 cases respectively. Atypical mitosis (Fig 2A) and necrosis (Fig 3) were noted in all 7 cases. Osseous metaplasia (Fig 2C), prominent neutrophilic infiltraion and vascular proliferation were seen in 1, 4 and 4 cases respectively (Table 2). 
Table 1: Summary of clinical features

\begin{tabular}{|c|c|c|c|c|c|c|}
\hline Case No. & Age (yrs) / Sex & Neck swelling & $\begin{array}{c}\text { Duration } \\
\text { (Month) }\end{array}$ & Hoarseness & Dysphagia & Lymphadenopathy \\
\hline 1 & $45 / \mathrm{F}$ & + & 4 & & & \\
\hline 2 & $57 / \mathrm{F}$ & + & 4 & & & \\
\hline 3 & $76 / F$ & + & 5 & + & + & \\
\hline 4 & $60 / \mathrm{M}$ & + & 7 & & & + \\
\hline 5 & $70 / \mathrm{F}$ & + & 6 & & + & + \\
\hline 6 & $65 / \mathrm{M}$ & + & 8 & + & + & \\
\hline 7 & $70 / \mathrm{F}$ & + & 6 & & & \\
\hline
\end{tabular}

Table 2: Summary of histopathological findings

\begin{tabular}{|c|c|c|c|c|c|c|c|c|c|c|c|}
\hline \multirow{2}{*}{$\begin{array}{l}\text { Case } \\
\text { No }\end{array}$} & \multirow{2}{*}{$\begin{array}{l}\text { Size of } \\
\text { tumor }\end{array}$} & \multirow{2}{*}{$\begin{array}{l}\text { Subtype / } \\
\text { Associated } \\
\text { carcinoma }\end{array}$} & \multicolumn{3}{|c|}{ Invasion } & \multirow{2}{*}{ 흥 } & \multirow{2}{*}{$\frac{n}{80}$} & \multirow{2}{*}{$\begin{array}{l}\text { Mitoses } \\
(>5 / h p f)\end{array}$} & \multirow{2}{*}{$\begin{array}{l}\text { Osseous } \\
\text { metaplasia }\end{array}$} & \multirow{2}{*}{$\begin{array}{l}\text { Neutrophilic } \\
\text { Infiltration }\end{array}$} & \multirow{2}{*}{$\begin{array}{l}\text { Vascular } \\
\text { proliferation }\end{array}$} \\
\hline & & & Muscular & Neural & Capsular & & & & & & \\
\hline 1 & $13 \mathrm{~cm}$ & & & & & + & + & + & & & \\
\hline 2 & $11 \mathrm{~cm}$ & Spindle cell type & & & + & + & + & + & + & & \\
\hline 3 & $19 \mathrm{~cm}$ & Squamoid cell type & & + & & & + & + & & + & + \\
\hline 4 & $9 \mathrm{~cm}$ & $\begin{array}{l}\text { Associated } \\
\text { Micropapillar }\end{array}$ & & & & & + & + & & & \\
\hline 5 & $15 \mathrm{~cm}$ & Spindle cell type & + & & & & + & + & & + & + \\
\hline 6 & $26 \mathrm{~cm}$ & Spindle cell type & + & & & & + & + & & + & + \\
\hline 7 & $11 \mathrm{~cm}$ & & + & & & & + & + & & + & + \\
\hline
\end{tabular}

\section{DISCUSSION}

Anaplastic carcinoma is also known as undifferentiated, dedifferentiated, sarcomatoid carcinoma. ${ }^{2,3}$ In our study, anaplastic carcinoma comprised $11.9 \%$ of all thyroid carcinomas which is more than in the studies done by Caccanjaeu et al and $\mathrm{Nel} \mathrm{C} \mathrm{J} \mathrm{et} \mathrm{al} \mathrm{who} \mathrm{found} \mathrm{the} \mathrm{incidence} \mathrm{to}$ be $3 \%-5 \%$ of all thyroid carcinoma. ${ }^{4,5}$ The tumor is usually seen in the elderly above 50 years of age with a mean age of 66.6 years. ${ }^{2,3,6}$ In our study, one case had an age of less than 50 years, however the mean age was 63 years, which is similar to what was found in other literature. ${ }^{4}$

The patients usually presented with a rapidly growing mass that frequently had an extra thyroid extension that led to hoarseness, dysphagia and dyspnea., 4, 7 The main presenting feature of all of our cases was swelling of the neck with a mean duration of 5.7 months. On FNAC, these tumors yielded a highly cellular aspirate containing large pleomorphic malignant cells. These malignant cells had either a macrophage like, spindle cell like or squamoid appearance. The background was mostly dirty with frequent necrotic debris and showed inflammation and scant colloid. ${ }^{8}$ The bizarre tumor cells along with a clinical history of a rapidly increasing mass usually allows for an easy diagnosis. However, marked fibrosis may lead to inadequate sampling and follicular adenoma rarely shows severe nuclear atypia.
On cytology, metastatic tumors also should be kept in mind as a differential diagnosis. ${ }^{8,9}$ These tumors are commonly widely invasive with frequent invasion into the surrounding muscles and other structures of the neck..$^{4,7}$ In our study, 3 cases had muscle infiltration and 2 cases each with lymphatic emboli and cervical lymphadenopathy. These tumors usually present with large masses and appear fleshy on the cut surface with hemorrhagic and necrotic areas. ${ }^{2}$ In our study, on gross examination 4 and 3 cases showed necrosis and hemorrhage respectively. Morphologically, the cells showed extreme pleomorphism with a wide spectrum of patterns. ${ }^{1,3}$ Different common patterns include epithelial features, spindle cell features, sarcomatoid features and squamoid features along with prominent giant cells. ${ }^{2,3}$ The cells exhibited fascicular or storiform patterns of growth. ${ }^{3}$ Also, heavy neutrophilic infiltration, prominent vascularization, cartilaginous and osseous metaplasia are known. $3,7,10$

Lymphovascular emboli are a common feature of this carcinoma. ${ }^{3}$ We found only 2 cases with emboli. Commonly, these tumors also show microscopic coagulative necrosis, ${ }^{7}$ which we found in all 7 cases. Risk factors may include iron deficiency, long standing goiter, history of radiation or previous papillary carcinoma. ${ }^{2,3,11}$

A history of goiter is known to be found in up to $80 \%$ of affected patients. ${ }^{2}$ We could not retrieve a proper history in 
all of the cases. In 2 cases, a long standing history of goiter was documented. Associated focus of papillary carcinoma was seen in 1 case and the other case showed prominent papillary formation without the characteristic nuclear feature of papillary carcinoma. In all our cases numerous abnormal mitoses were noted which is a similar finding in other studies. $^{2}$

The differential diagnosis of anaplastic carcinoma includes sarcoma, solid variant of papillary carcinoma, poorly differentiated (insular) carcinoma, thymic-related tumors, large cell lymphoma, osteclastoma, hemangiopericytoma, metastatic carcinoma, parathyroid carcinoma, Riedel thyroiditis, reactive benign process such as reparative epithelial atypia in benign tumor (due to infarction or following fine needle aspiration) or florid granulation tissue due to organization of infarcted tumor. ${ }^{1,3}$ Unusual variants resemble sarcomas like fibrosarcoma, malignant fibrous histiocytoma, angiosarcoma and rhabdomyosarcoma. ${ }^{3}$ For practical purposes, any sarcoma like tumor of the thyroid can be reported as anaplastic carcinoma because the distinction between sarcoma and anaplastic carcinoma is not so important as they are both an aggressive malignancy. ${ }^{1}$

Papillary carcinomas have characteristic nuclear features while insular carcinoma shows typical islands with the presence of microfollicles. ${ }^{3}$ Lymphoma and metastatic carcinoma may only occasionally show the degree of atypia as seen in anaplastic carcinoma. Both of them can usually be distinguished by clinical correlation and immunomarkers. ${ }^{1}$ The paucicellular variant of anaplastic carcinoma can be confused with Riedel's thyroiditis which has better prognosis. However, Riedel's thyroiditis shows minimal atypia and absence of tumor emboli. ${ }^{1,3}$ The periphery of this tumor is known to show adenomatous changes or a well differentiated papillary or follicular carcinoma. ${ }^{1,2}$ We found adenoamtous changes in 3 cases in the peripheral areas, while 4 other cases did not show any change. Most patients with anaplastic carcinoma survive less than 6 months following the diagnosis. ${ }^{2}$ The rare survivor has completely resectable small tumors less than $5 \mathrm{~cm}$ in size and is treated with chemotherapy and radiotherapy. ${ }^{1,2}$

\section{CONCLUSION}

Anaplastic carcinoma of the thyroid is an uncommon but markedly aggressive tumor which is more commonly seen in areas of endemic thyroid disease. It is important to diagnose them early by differentiating these tumors from other entities and start these patients on aggressive therapy.

\section{REFERENCES}

1. Chan JK. Tumors of the thyroid and parathyroid glands. In: Fletcher CDM. Diagnostic histopathology of tumors. 2nd (eds), Philadelphia Churchill Livingstone; 2005. pp 959-1023.

2. LiVolsi VA, Montone K, Sack M. Pathology of thyroid disease. In: Sternberg SS, editior. Diagnostic surgical pathology. 3rd (eds), Lippincott, Williams \& Wilkins; 1999. pp 529-571.

3. Rosai J. Thyroid gland. In: Ackerman's surgical pathology. 9th (eds), Mosby: Harcourt Brace Company; 2005. pp 493-554.

4. Carcangiu ML, Steeper T, Zampi G, Rosai J. Anapalstic thyroid carcinoma: A study of 70 cases. Am J Clin pathol 1985;83:135-58.

5. Nel CJ, van Heerden JA, Goellner JR. Anaplastic carcinoma of the thyroid: a clinicopthologic study of 82 cases. Mayo Clin Proc 1985;60:51-8.

6. Venkatesh YS, Ordoez NG, Schultz PN, Hickey RC, Goepfert H, Samaan NA. Anaplastic carcinoma of the thyroid - A clinicopathologic study of 121 cases. Cancer 1990;66:321-30.

7. Rosai J, Saxen EA, Woolner L. Undifferentiated and poorly differentiated carcinoma. Semin Diag Pathol 1985;2:123-6.

8. Orell SR, The thyroid gland. In: Manual and Atlas of fine needle aspiration cytology. 3 ed. Churchill Livingstone: Sweden; 1999. pp 96-124.

9. Lowhagen T, Sprenger E. Cytologic presentation of thyroid tumors in aspiration biopsy smears. Acta Cytol 1974;18:192-7.

10. Blasius S, Edel G, Grunert J, Bocker W, Schmid KW. Anaplastic thyroid carcinoma with osteosarcomatous differentiation. Pathol Res Pract 1994;190:507-10.

11. Fisher ER, Gregorio R, Shoemaker R, Horvat B, Hubay C. The differentiation of so called "giant-cell" and "spindle-cell" undifferentiated thyroidal neoplasms. Am J Clin Pathol 1974;61:680-9. 